\title{
Flame Retardant Performance of Wood Treated with Flame Retardant Chemicals*1
}

\author{
Hee-Jun Park*2, Mingyu-Wen*2†, Sang-Hun Cheon*3, \\ Jung-woo Hwang*4, and Seung-Won $\mathrm{Oh}^{* 4}$
}

\begin{abstract}
This study investigated the flame retardant performance of developed four types of flame retardant chemicals (FRC), FRC-A, B, C and D. Four kinds of soft wood species, Sugi (Cryptomeria), Spruce (Picea abies), Hinoki (Chamaecyparis obtusa) and Korean pine (Pinus koraiensis), were used. The wood specimens were treated by spreading the FRC on the surface with different quantities, 30, 50,70,90,110 g/ $\mathrm{m}^{2}$, respectively. The charred area, charred length, after flame time and after glow time were tested. And their suitabilities as incombustible materials were evaluated. The specimen treated by FRC-D showed better incombustible properties than others, even though with lower quantity. Therefore it is supposed that the FRC-D could be able to be applied on the cultural heritage, such as Korean wooden house for preventing fire.
\end{abstract}

Keywords : flame retardant chemical (FRC), flame retardant performance, charred area, charred length

\section{INTRODUCTION}

Wood materials with its natural qualities and beauty of grain always is favored in the field of residential, commercial and industry building construction, as well as for indoor furnishing. The need for consumer protection, coupled with the new regulations and environmental concerns, fire retardant treatment of wood materials to improve the fire performance is increasingly demanded. Chemical treatment can significantly improve the fire performance of wood materials, by so doing, widens their utilization options
(Chuang et al., 2008).

Currently, many types of flame retardants are used for wood materials. There are three major ways to enhance the fire performance of wood, including (1) impregnating a fire retardant agent into the wood; (2) an agent mixed with inorganic composite and (3) fire retardant spreading applied as paint (Wang et al., 2004). Appling paint treatment is found to be the fast and convenient way, especially for existing ancient architectural buildings, such as wooden houses. Under the heat at the earlier stage of fire, the paint on the achieve flame retardancy by form

*1 Received on August 7, 2012; accepted on September 18, 2012

*2 Department of Housing Environmental Design and Research Institute of Human Ecology, College of Human Ecology, Chonbuk National University, Jeonju 561-756, Korea

*3 R\&D Center, Samhwa Paints Inc. Co., Ltd., 677 Seonggok-dong, Danwon-gu, Ansan 425-835, Korea

*4 Department of Wood Science \& Technology, College of Agriculture Life Science, Chonbuk National University, Jeonju 561-756, Korea

† Corresponding author : Mingyu-Wen (e-mail: jlwenmingyu@hotmail.com) 
Hee-Jun Park, Mingyu-Wen, Sang-Hun Cheon, Jung-woo Hwang, and Seung-Won Oh

Table 1. Moisture content of species

\begin{tabular}{ccccc}
\hline Species & Spruce & Sugi & Hinoki & Korea pine \\
\hline \hline MC $(\%)$ & 10.34 & 9.68 & 12.12 & 9.93 \\
\hline
\end{tabular}

ing physical barrier to deter heat and mass transfer between the gas and the condensed phases. Thus rescue time could be saved in the emergency situation.

It is well known that wood treated with compounds containing nitrogen, phosphorus, halogens, and boron such as ammonium phosphate, ammonium halide, boric acid and borax to improve fire retardance and accelerate the formation of a carbonized layer on the materials. It is proposed that such chemicals can lead to a lowering of the decomposition temperature and a higher char yield (Zhang and Chen, 2011 Kunze et al., 2004). In addition, the intumescent fire retardant (IFR) system has recently aroused a great attention in the fire retardation of polymers for many advantages such as low smoke, low toxicity and halogen free. Typically, the IFR system is composed of three components, i.e. an acid source, a carbonization compound and a blowing agent (Gao et al., 2005; Lv et al., 2009). For example, ammonium polyphosphate (APP), pentaerythritol and melamine are a well-known intumescent flame retardant formulation. In polymeric intumescent spreadings endothermic chemical reactions are exploited to absorb heat and to produce bubbles causing the material to swell. A carbonaceous or silicate layer of a multi-cellular structure is formed with simultaneous release of non-flammable gases (Choi, 2011; Marney and Russell, 2008).

In this study four types of water soluble flame retardant chemicals (FRC-A, B, C and D) were developed and the flame retardant performance of four kinds of wood species treated by the FRCs were evaluated. The better formulation was selected for further wood flame retardant study for the application for culture buildings.

\section{MATERIALS and METHODS}

\subsection{Materials}

Four kinds of softwood wood species were used: Sugi (Cryptomeria), Spruce (Picea abies), Hiniki (Chamaecyparis obtusa) and Korean pine (Pinus koraiensis). The moisture contents of all wood species are shown in Table 1 . The specimens were cut into $300 \times 200 \mathrm{~mm}$ blocks, with thickness of $10 \mathrm{~mm}$.

The developed four types of FRC were spread on the surface of specimens using a brush, and then the specimens were air dried. The quantity was $30,50,70,90,110 \mathrm{~g} / \mathrm{m}^{2}$, respectively. Prior to flammability testing, the air dried specimens were conditioned for over $48 \mathrm{hr}$. at $50 \pm 2{ }^{\circ} \mathrm{C}$. For comparison, control specimens without spreading were also prepared. Three replications for each spreading were tested. The FRC-A, B, C and D are synthesized in lab. Their main components and spreading quantities are shown in Table 2.

\section{2. $45^{\circ}$ Flammability Test}

The $45^{\circ}$ flammability test was conducted according to Notification of Korean National Emergency Management Agency standard, No. 2009-31 (2009). The specimens were clamped with a steel holder and kept steady at the heating flame at an angle of 45 degrees. The heating flame, adjust to a length of $65 \mathrm{~mm}$ from the bottom. The duration of heating by the flame was set at $2 \mathrm{~min}$. The after flame time (duration 
Flame Retardant Performance of Wood Treated with Flame Retardant Chemicals

Table 2. Properties of flame retardant chemicals

\begin{tabular}{|c|c|c|c|c|c|c|c|}
\hline Item & & Actual $\mathrm{s}$ & $\begin{array}{c}\text { preading } \\
\left(\mathrm{g} / \mathrm{m}^{2}\right) \\
\end{array}$ & quanti & & $\begin{array}{c}\text { Solid content } \\
(\%)\end{array}$ & Main components \\
\hline FRC-A & 37.9 & 63.2 & 88.5 & 113.8 & 139.1 & 20.8 & $\begin{array}{l}\text { corecell acrylic dispersion / polyurethane com- } \\
\text { pound and poly phosphate/addictive agent }= \\
75 \% / 15 \% / 10 \%\end{array}$ \\
\hline FRC-B & 39.3 & 65.4 & 91.6 & 117.8 & 143.9 & 20.1 & $\begin{array}{l}\text { corecell acrylic dispersion / polyurethane com- } \\
\text { pound and poly phosphate / triethylphosphate } \\
\text { (TEP) } / \text { addictive agent }=70 \% / 10 \% / 5 \%\end{array}$ \\
\hline FRC-C & 37.8 & 62.9 & 88.1 & 113.3 & 138.4 & 20.9 & $\begin{array}{l}\text { corecell acrylic dispersion / polyurethane com- } \\
\text { pound, polyphosphate and nitrogen / addictive } \\
\text { agent }=75 \% / 15 \% / 10 \%\end{array}$ \\
\hline FRC-D & 30.0 & 50.0 & 70.0 & 90.0 & 110.0 & 26.3 & $\begin{array}{l}\text { Organic phosphorus compound and amonium } \\
\text { polyphosphate (APP) } / \text { addictive agent }=75 \% \\
/ 25 \%\end{array}$ \\
\hline
\end{tabular}

Note. Each value is average of three replications.

of continuous flaming after removing the heating source) was observed. The after glow time (state of non-flame combustion after cessation of the flame) was also recorded. The charred area and length of tested specimens were measured after brushing and removing the charred surface.

\subsection{The Analysis of Morphology of the Residual Charred Outer Layers}

The digital morphology of the residual charred outer layers of Hinoki was observed by Digital Megascope system IMSD-12A-088 (Alphasystec. Co. kr) with lens set of $\times 300$ lens.

\section{RESULTS and DISCUSSION}

\subsection{Flame Retardant Performance of Wood Specimen Treated by FRC- $A, B, C$ and $D$}

The flame retardant performance of different wood species treated by developed FRCs were shown in Table 3. According to Notification of
Korean National Emergency Management Agency standard, No. 2009-31 (2009) the charred area was required $50 \mathrm{~cm}^{2}, 20 \mathrm{~cm}$ for charred length, $10 \mathrm{sec}$. for after flame and $30 \mathrm{sec}$. for after glow. It is obviously that the controlled specimens of four species were all not able to meet the requirement, especially in case of charred area and after glow. The charred area as a function of spreading quantity was shown in Figs.1 4. However, it is generally observed that no specific trend of variation in charred area as increasing spreading quantity was record for all species. The improvement of flame retardant performance of specimens treated by FRC-A, B and C were slightly compared with control specimen. Additionally, in view of FRC-A, $\mathrm{B}$, and $\mathrm{C}$, among them it is hard to discern the better flame retardant performance due to the absence of consistence trend. One the on hand, wood as uneven-textured material, it is hard to get the same part on the same wood. When the part where resin exits is heated, the leaked out resin is one of the reasons responsible for the inferior flame retardant performance. Furthermore, due to the spreading treatment only the surface of wood, rather than impregnation, the deviation 
Hee-Jun Park, Mingyu-Wen, Sang-Hun Cheon, Jung-woo Hwang, and Seung-Won Oh

Table 3. Flame retardant performances of wood specimen treated by FRC-A, B, C, D

\begin{tabular}{|c|c|c|c|c|c|c|c|c|c|c|c|c|c|c|c|c|c|}
\hline \multirow{2}{*}{$\begin{array}{l}\text { Wood } \\
\text { species }\end{array}$} & \multirow{2}{*}{$\begin{array}{c}\text { Spreading } \\
\text { quantity }\end{array}$} & \multicolumn{4}{|c|}{ Charred area $\left(\mathrm{cm}^{2}\right)$} & \multicolumn{4}{|c|}{ Charred Length $(\mathrm{cm})$} & \multicolumn{4}{|c|}{ After flame (sec.) } & \multicolumn{4}{|c|}{ After-glow (sec,) } \\
\hline & & $\begin{array}{c}\text { FRC- }^{-} \\
\text {A }\end{array}$ & $\begin{array}{c}\mathrm{FRC}^{-} \\
\mathrm{B}\end{array}$ & $\begin{array}{c}\mathrm{FRC}^{-} \\
\mathrm{C}\end{array}$ & $\begin{array}{l}\text { FRC- }^{-} \\
\text {D }\end{array}$ & $\begin{array}{c}\text { FRC- }^{-} \\
\mathrm{A}\end{array}$ & $\begin{array}{c}\mathrm{FRC}^{-} \\
\mathrm{B}\end{array}$ & $\begin{array}{c}\mathrm{FRC}^{-} \\
\mathrm{C}\end{array}$ & $\begin{array}{l}\text { FRC- }^{-} \\
\text {D }\end{array}$ & $\begin{array}{c}\mathrm{FRC}^{-} \\
\mathrm{A}\end{array}$ & $\begin{array}{c}\text { FRC- }^{-} \\
\text {B }\end{array}$ & $\begin{array}{c}\text { FRC- }^{-} \\
\text {C }\end{array}$ & $\begin{array}{c}\mathrm{FRC}^{-} \\
\mathrm{D}\end{array}$ & $\begin{array}{c}\text { FRC- }^{-} \\
\text {A }\end{array}$ & $\begin{array}{c}\mathrm{FRC}^{-} \\
\mathrm{B}\end{array}$ & $\begin{array}{c}\mathrm{FRC}^{-} \\
\mathrm{C}\end{array}$ & $\begin{array}{c}\text { FRC- }^{-} \\
\text {D }\end{array}$ \\
\hline Control & 0 & 72.9 & 72.9 & 72.9 & 72.9 & 14.8 & 14.8 & 14.8 & 14.8 & 2.8 & 2.8 & 2.8 & 2.8 & 42.8 & 42.8 & 42.8 & 42.8 \\
\hline \multirow{5}{*}{ Sugi } & 30 & 44.3 & 46.7 & 49.4 & 38.6 & 9.6 & 9.7 & 10.0 & 8.3 & 0.0 & 0.0 & 0.0 & 5.3 & 21.8 & 0.0 & 19.4 & 0.1 \\
\hline & 50 & 63.9 & 53.1 & 61.2 & 36.9 & 11.8 & 10.0 & 11.1 & 8.2 & 2.5 & 0.0 & 0.0 & 0.45 & 15.3 & 0.0 & 12.6 & 0.2 \\
\hline & 70 & 53.3 & 42.4 & 56.4 & 31.6 & 9.9 & 9.4 & 11.4 & 7.8 & 3.3 & 0.0 & 10.3 & 5.1 & 1.8 & 0.0 & 5.3 & 0.0 \\
\hline & 90 & 89.0 & 42.6 & 64.8 & 34.9 & 12.2 & 8.5 & 11.3 & 7.8 & 5.1 & 3.1 & 1.6 & 2.6 & 1.6 & 0.0 & 8.1 & 0.0 \\
\hline & 110 & 70.7 & 58.1 & 80.5 & 28.1 & 11.2 & 10.7 & 14.0 & 7.3 & 2.8 & 2.5 & 0.0 & 0.0 & 1.7 & 0.0 & 0.0 & 0.0 \\
\hline \multirow[t]{3}{*}{ Control } & 0 & 62.2 & 62.2 & 62.2 & 62.2 & 11.7 & 11.7 & 11.7 & 11.7 & 1.8 & 1.8 & 1.8 & 1.8 & 18.7 & 18.7 & 18.7 & 18.7 \\
\hline & 30 & 29.2 & 38.5 & 28.1 & 28.3 & 6.8 & 8.8 & 7.6 & 6.8 & 0.0 & 7.2 & 3.2 & 2.2 & 5.1 & 2.7 & 0.0 & 2.0 \\
\hline & 50 & 26.2 & 45.9 & 36.1 & 23.2 & 7.8 & 9.8 & 8.7 & 6.4 & 12.5 & 1.9 & 2.0 & 0.6 & 0.0 & 0.0 & 1.8 & 0.6 \\
\hline \multirow[t]{3}{*}{ Hinoki } & 70 & 39.9 & 31.6 & 48.8 & 33.7 & 9.4 & 8.1 & 10.2 & 7.6 & 2.1 & 2.3 & 0.0 & 1.2 & 0.0 & 0.0 & 0.0 & 0.3 \\
\hline & 90 & 50.1 & 38.8 & 48.0 & 24.4 & 10.4 & 8.4 & 11.1 & 6.8 & 0.0 & 4.0 & 6.7 & 0.7 & 0.0 & 0.0 & 10.4 & 0.1 \\
\hline & 110 & 12.8 & 39.3 & 60.3 & 27.4 & 5.3 & 9.9 & 12.3 & 7.3 & 0.0 & 0.0 & 0.0 & 0.8 & 0.0 & 0.0 & 5.5 & 0.0 \\
\hline \multirow[t]{3}{*}{ Control } & 0 & 85.9 & 85.9 & 85.9 & 85.9 & 14.6 & 14.6 & 14.6 & 14.6 & 5.2 & 5.2 & 5.2 & 5.2 & 13.6 & 13.6 & 13.6 & 13.6 \\
\hline & 30 & 71.4 & 74.6 & 78.8 & 48.6 & 12.6 & 13.2 & 12.5 & 9.4 & 3.6 & 3.7 & 0.0 & 2.3 & 0.0 & 0.0 & 7.2 & 0.0 \\
\hline & 50 & 90.3 & 93.5 & 86.0 & 32.3 & 13.9 & 15.1 & 15.1 & 7.9 & 5.9 & 2.9 & 4.7 & 0.7 & 0.0 & 0.0 & 0.0 & 0.0 \\
\hline \multirow{3}{*}{$\begin{array}{c}\text { Korean } \\
\text { pine }\end{array}$} & 70 & 65.5 & 76.8 & 87.4 & 33.7 & 11.3 & 12.2 & 14.2 & 8.4 & 0.0 & 4.7 & 9.5 & 0.3 & 0.0 & 0.0 & 0.0 & 0.0 \\
\hline & 90 & 67.2 & 93.8 & 72.9 & 26.8 & 12.0 & 14.2 & 13.8 & 7.8 & 2.8 & 2.3 & 7.0 & 0.5 & 0.0 & 0.0 & 0.0 & 0.0 \\
\hline & 110 & 75.8 & 63.9 & 55.6 & 19.4 & 13.1 & 11.9 & 11.2 & 7.4 & 0.0 & 1.9 & 0.0 & 0.7 & 0.0 & 0.0 & 0.0 & 0.0 \\
\hline \multirow[t]{3}{*}{ Control } & 0 & 67.7 & 67.7 & 67.7 & 67.7 & 11.6 & 11.6 & 11.6 & 11.6 & 1.5 & 1.5 & 1.5 & 1.5 & 12.1 & 12.1 & 12.1 & 12.1 \\
\hline & 30 & 69.1 & 53.5 & 63.8 & 36.7 & 12.1 & 45.8 & 11.3 & 7.8 & 3.3 & 3.3 & 0.0 & 2.3 & 0.0 & 0.0 & 12.3 & 0.0 \\
\hline & 50 & 60.1 & 63.5 & 76.9 & 28.2 & 11.0 & 11.0 & 13.2 & 6.8 & 4.8 & 5.4 & 7.4 & 0.3 & 3.7 & 0.0 & 0.0 & 0.0 \\
\hline \multirow[t]{3}{*}{ Spruce } & 70 & 63.9 & 52.3 & 73.6 & 27.1 & 11.7 & 10.3 & 12.5 & 7.3 & 3.9 & 0.0 & 0.0 & 0.2 & 6.4 & 0.0 & 0.0 & 0.0 \\
\hline & 90 & 76.4 & 47.3 & 70.2 & 25.4 & 11.9 & 10.0 & 11.2 & 7.0 & 5.8 & 6.3 & 2.3 & 0.6 & 0.0 & 0.0 & 9.5 & 0.0 \\
\hline & 110 & 70.4 & 59.8 & 59.2 & 28.1 & 11.9 & 11.3 & 11.9 & 7.3 & 2.2 & 5.4 & 2.8 & 0.2 & 0.0 & 0.0 & 9.0 & 0.0 \\
\hline
\end{tabular}

Note : Each value is average of three replications.

between wood species is not obvious. On the other hand, the FRC-A, B and $\mathrm{C}$ which with the main component of corecell acrylic dispersion, polyurethane and polyphosphate are not so effect enough to resist those disadvantages. Therefore, as increased spreading quantity, they did not exhibit consistence decline trend. In the cases of
Korean pine, there is no apparently effect regardless of spreading FRC-A, B or C, all of which were fail to meet the criterion. This may be attributed to the characteristic of Korean pine, with abundance knots and resin inferior to fire prevention.

In contrast to FRC-A, B, and C, as for 


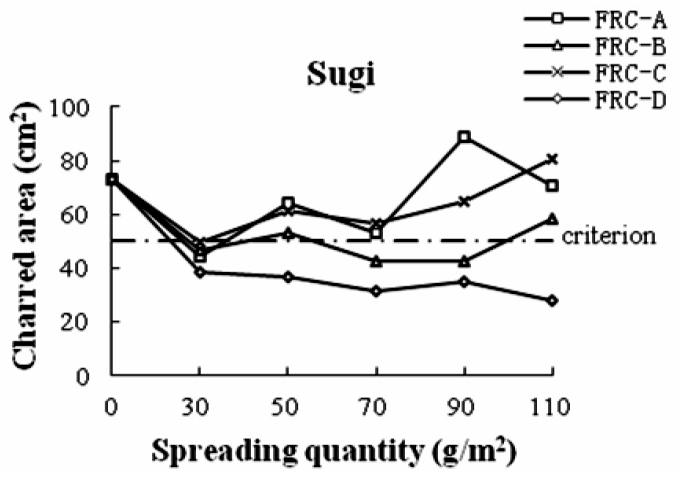

Fig. 1. Charred area of treated Sugi specimen as a function of spreading quantity.

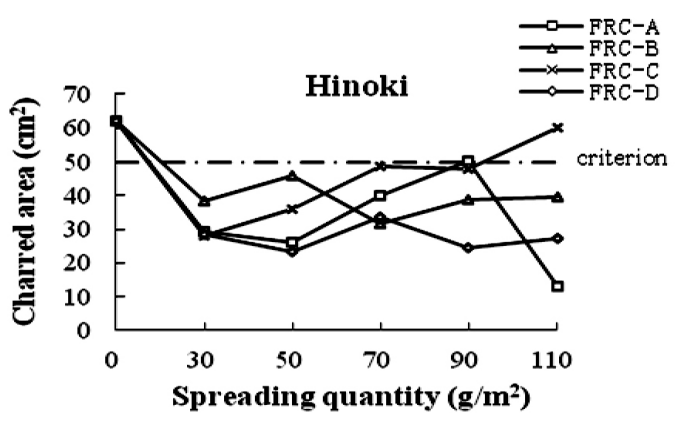

Fig. 2. Charred area of treated Hinoki specimen as a function of spreading quantity.

FRC-D, initially there is a drastic reduction in the charred area, even though with lower quantity of $30 \mathrm{~g} / \mathrm{m}^{2}$, at which charred area are relative lower to be in accordance with the criterion for all specimens, and trend tends to flat finally. Consequently, this confirmed the good flame retardant performance of FRC-D, APP based intumescent formulation. Generally, the function of flammable retardant in cellulose material is to increase the char at the cost of flammable volatile products. Thus good flame retardant can make wood decompose at lower temperature $\left(<300^{\circ} \mathrm{C}\right.$, where cellulose, the critical component of wood, decomposes though the first type of reaction and products more char and corre-

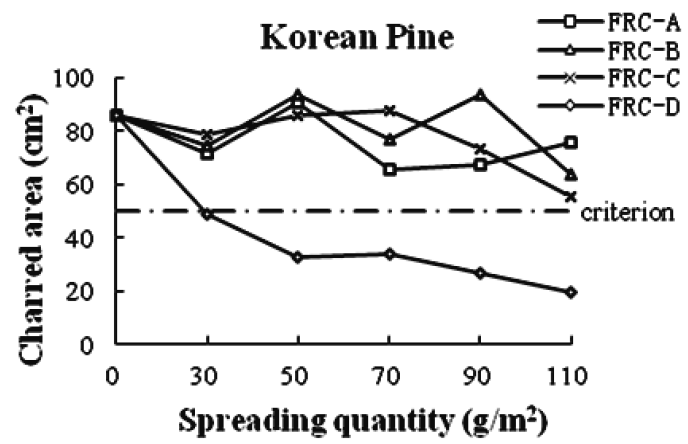

Fig. 3. Charred area of treated Korean pine specimen as a function of spreading quantity.

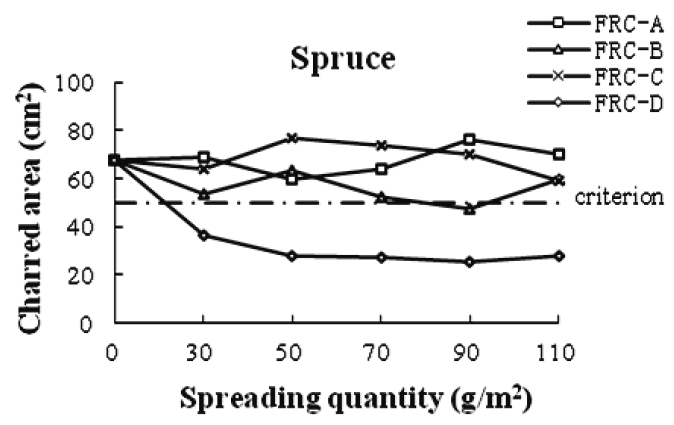

Fig. 4. Charred area of treated Spruce specimen as a function of spreading quantity.

spondingly less flammable volatiles (WladykaPrzbylak and Kozlowski, 1999). It is observed that upon heating intumescent fire-retardant formulation, a layer of foamy carbonaceous char is produced, which protects the polymer surface from the flames. This is confirmed by following observation of residual char morphology. When ignited, wood undergo thermal degradation, forming combustible volatile compounds which become involved in the propagation of fire. Theoretically, this layer acts as a physical barrier that hinders the transfer of heat from the flame to the material.

Furthermore, the difference of formulation is the one of the main factors responsible for the 
Hee-Jun Park, Mingyu-Wen, Sang-Hun Cheon, Jung-woo Hwang, and Seung-Won Oh

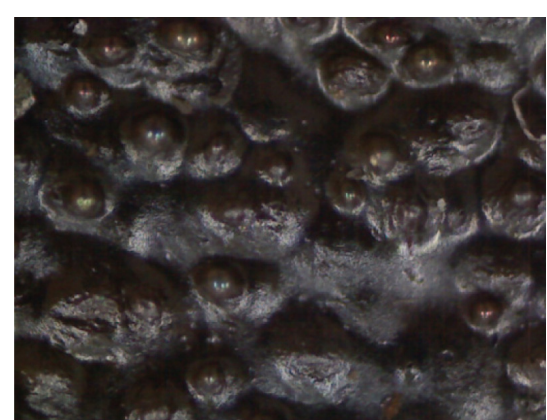

FRC-A

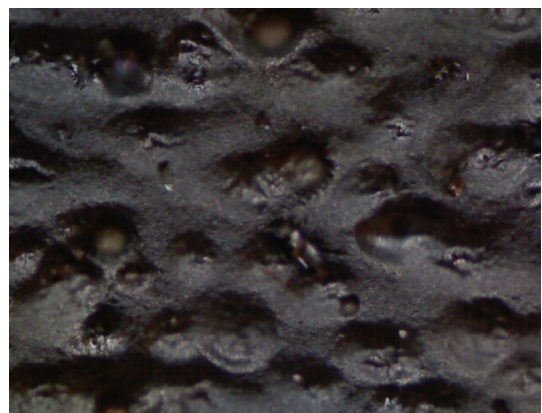

FRC-C

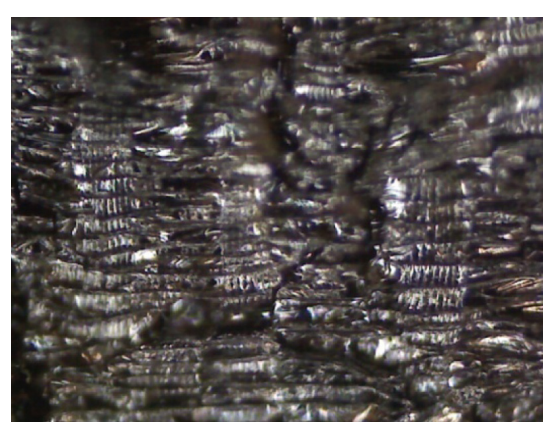

Control

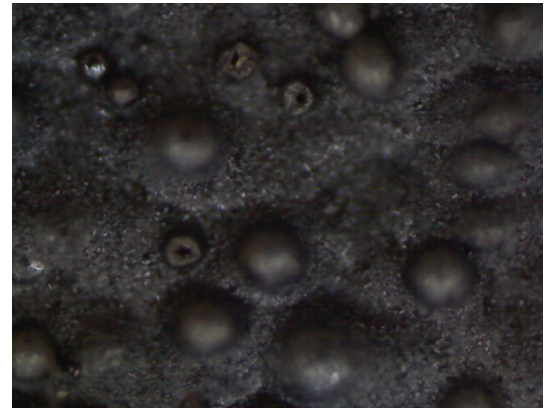

FRC-B

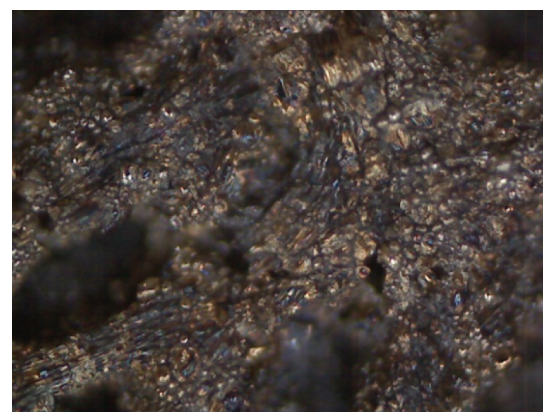

FRC-D

Fig. 5. The morphology of the residual charred outer layers $(\times 300$ lens).

(FRC-A, FRC-B, FRC-C, FRC-D, Control)

deviation in the flame retardant performance of FRC- A, B, C and D. In concern with the economic, for the application of FRC-D, at least 30 $\mathrm{g} / \mathrm{m}^{2}$ is recommended. Compared with other study (Ho and Seong, 2012) using three kinds of commercial flame retardants, with main component of guanidine and polyphosphate re- spectively, even though spread two times with the quantity of $500 \mathrm{~m} \ell / \mathrm{m}^{2}$ and $200 \mathrm{~m} \ell / \mathrm{m}^{2}$, they failed to meet the flame retardant criterion. The satisfied flame retardant performance of FRC-D enable it should be potential flame retardant chemical applying for wood and heritage culture fire prevention. 


\subsection{The Morphology of Combusted Residual Charred out Layer}

Fig. 5 shows the photos of out charred layer of wood specimen treated by FRC-A, B, C and D. From the char residue it can be observed that compared with control specimen (Control), FRC-A, B, and D all formed a condensed phase charred area during combustion. However, a lot of small bubbles existed on the surface of the charred layer of FRC-D, different from FRC-A, $\mathrm{B}, \mathrm{C}$ and Control. As the main component of FRC-D, APP is reported would be transformed into ultra-phosphate substance with elimination of ammonium and water (Drevelle et al., 2004; Zhong et al., 2007). The existed bubble form, on the one hand was caused by the released large quantities of gases impacted flame retardant system in the process of burning and decomposition. On the other hand, such a structure can attribute to prevent the exchange of the fuels and the oxygen outside between the condensed phase and the gas phase, and hold amount of the decomposition gas. The incombustible ammonia released from the thermal decomposition of APP can dilute air and simultaneously remove part of the generated heat (Gao et al., 2004).

The morphology of compact outer surface further evidence of the fire retardant is the intumescent flame retardants which provide a barrier to resist the transfer of heat and mass during a fire and subsequently effectively prevent the exposure of heat and combustible gas to flame retardant system. As a result, FRC-D showed the better flame retardant performance, confirmed by combustion test result above. In addition, in view of FRC-A, B and $\mathrm{C}$, there is presence of some honey shape layers formed on the surface, however they were fail to prevent combustion effectively as the result stated above.

\section{CONCLUSION}

In this paper, the flame retardant performance of developed four types of flame retardant chemicals (FRC), FRC-A, B, C and D was investigated on four kinds of wood species treated with the FRCs, in attempt to selected the better formulation for further study. The conclusions are as follows:

(1) The results of The flammability test show that the FRC-D, APP based intumscent formulation, was detected to be superior to others and present desirable flame retardant performance. In concern with economic, at least $30 \mathrm{~g} / \mathrm{m}^{2}$ is recommended for its application.

(2) The morphology of combusted residual charred out layers was observed by microscope. The result further confirmed the conclusion above. The morphology of char formed by FRC-D indicates that the char layer could swell well to form a barrier to resist the transfer of heat and mass during a fire.

(3) For the consideration of good flame retardant performance of FRC-D, it is supposed that the FRC-D could be potential to able to be applied on the cultural heritage, such as Korean wooden house for preventing fire, compared with other commercial flame retardants.

\section{ACKNOWLEDGMENT}

The present work is supported by the research fund of the Rural Development Administration, Korea, under project No. PJ0079674.

\section{REFERRNCE}

1. Chuang, C.-S., C.-H. Ko, K.-C. Tsai, M.-K. Wang, C.-C. Ou, and I.-L. Shiau. 2008. Effects of intumescent formulation for acrylic-based spre- ading on flame-retardancy of painted red lauan (Parashorea spp.) thin plywood. Wood Sci. Technol. 
42: $593 \sim 607$.

2. Wang, Q., J. J. Li, and E. Winandy. 2004. Chemical mechanism of fire retardance of boric acid on wood. Wood Sci. Technol. 38: 375 389.

3. Zhang, Q., and Y. Chen. 2011. Synergistic effects of ammonium polyphosphate/melamine intumescent system with macromolecular char former in flameretarding polyoxymethylene. J. Polym. Res. 18: $293 \sim 303$.

4. Kunze, R., Schartel, B., Bartholmai, M., Neubert, D., and Schriever, R. 2002. TG-MS and TG-FTIR applied for an unambiguous thermal analysis of intumescent spreading. J. Therm. Anal. Calorim. 70: 897909 .

5. Gao, M., B. Ling, S. Yang, and M. Zhao. 2005. Flame retardance of wood treated with guanidine compounds characterized by thermal degradation behavior. J. Anal. Appl. Pyrolysis 73: 151 156 .

6. Lv, P., Z. Wang, Y. Hu, and M. Yu. 2009. Study on effect of polydimethylsiloxane in intumescent flame retardant polypropylene. J. Polym Res. 16: $81 \sim 89$.

7. Choi, J.-M. 2011. A study on combustion characteristics of fire retardant treated Pinus Densiflora and Pinus Koraiensis. Mokchae Konghak 39(3): $244 \sim 251$.

8. Marney, D. C. O., and L. J. Russell. 2008. Com- bined fire retardant and wood preservative treatments for outdoor wood applications a review of the literature. Fire Technology 44: 114.

9. Notification No. 2009-31. Korean National Emergency Management Agency standard. 2009.

10. Wladyka-Przbylak, M., and R. Kozlowski. 1999. The thermal characteristics of different intumescent spreadings. Fire Mater. 23: $33 \sim 43$.

11. Drevelle, C., S. Duquesne, M. Le. Bras, J. Lefebvre, R. Delobel, A. Castrovinci, C. Magniez, M. Vouters. 2004. Influence of ammonium polyphosphate on the mechanism of thermal degradation of an acrylic binder resin. J. Appl. Polym. Sci.94: $717 \sim 729$.

12. Zhong, H., D. Wu, P. Wei, P. Jiang, and Q. Li. 2007. Synthesis, haracteristic of a novel additive-type flame retardant containing silicon and its application in PC/ABS alloy. J. Mater. Sci. 42: 1010610112.

13. Ho, C. S. and H. G. Seong. 2012. Performance of some commercial flame retardants. 2012 proceedings of the Korean society of wood science and technology annual meeting. 174-175.

14. Gao, M., C. Sun, and K. Zhu. 2004. Thermal degradation of wood treated with guanidine compounds in air flammability study. J. Therm. Anal. Calorim. 75: $221 \sim 232$. 